\title{
A new station for monitoring electromagnetic fields in Duronia (Italy): experimental setup and first results
}

\author{
Paolo Palangio $\left({ }^{1}\right)$, Fabrizio Masci $\left({ }^{1}\right)$, Manuele Di Persio $\left({ }^{1}\right)$, Cinzia Di Lorenzo $\left({ }^{1}\right)$ and Elisabetta Lampis $\left({ }^{2}\right)$ \\ (1) Istituto Nazionale di Geofisica e Vulcanologia, L'Aquila, Italy
}

(') Geomagnetic System, Italy

\begin{abstract}
Since the end of 2007 a new electromagnetic field monitoring station has been in operation in Central Italy in the area of a village called Duronia. The station was created in the framework of the MEM (Magnetic and Electric fields Monitoring) Project composed of a team headed by the Abruzzo region. The main target of the MEM Project is to create in the Adriatic Area a network of observatories to monitor the environmental electromagnetic signals in the frequency band from $0.001 \mathrm{~Hz}$ to $100 \mathrm{kHz}$ (ULF-ELF-VLF). The peculiarity of the Duronia installation is the low electromagnetic background noise of the site and the low noise of the instrumentation. Here we show the experimental setup, with a brief discussion on the installed instrumentation and on the preliminaresults obtained in the first months of operation. The research activity is mainly focused on the analysis of the spectral structure of the Schumann Resonance in the range of frequencies [5.0-35.0]Hz, and the Ionospheric Alfvén Resonator in the range of frequencies [0.1-7.0] Hz and their evolution in time. Another target concerns the long-term monitoring of local magnetic field anomalies possiblelated to the local geodynamical processes.
\end{abstract}

Key words geomagnetic field - MEM project Schumann resonance - Ionospheric Alfvén Resonator

\section{Introduction}

The evolution of the measurement techniques and the ongoing research activity have a considerable importance for a better understanding of the environmental electromagnetic fields (Bianchi and Meloni, 2008). The main objectives of these studies are both to enhance the knowledge on the natural electromagnetic fields, and study the electromagnetic anomalies associated to anthropogenic sources, the well

Mailing address: Dr. Fabrizio Masci, Osservatorio Geofisico INGV, Castello Cinquecentesco, 67100 L'Aquila, Italy; e-mail: masci@ingv.it known man-made fields. The knowledge of how these anomalies are distributed in space and time can be useful to life improvement on our planet. On the other hand, the study of the non ionizing radiation effects on the biological tissues is a topical issue that needs an answer. The MEM Project was activated in the INGV (Italian Istituto Nazionale di Geofisica e Vulcanologia) Observatory of L'Aquila to study the environmental electromagnetic fields, both natural and artificial. The project started in 2005 and ended in 2007. The leader partner of the project is the Italian Abruzzo Region. The other partners are the Geomagnetic Observatory of L'Aquila, the Regional Environmental Agency of Molise Region, Italy, the University of Ferrara, Italy, the University of Tirana, Albania and the Geomagnetic Institute of Grocka, Beograd, Serbia. The principal purpose of the project was the development in Central Italy of a network of observatories to monitor the electromagnetic 
signals in the frequency band ranging from ULF to VLF. Currently the network consists of two monitoring stations, L'Aquila $\left(42^{\circ} 23^{\prime} \mathrm{N}\right.$, $13^{\circ} 19^{\prime} \mathrm{E}, 682 \mathrm{~m}$ a.s.1.) and Duronia $\left(41^{\circ} 39^{\prime} \mathrm{N}\right.$, $14^{\circ} 28^{\prime} \mathrm{E}, 910 \mathrm{~m}$ a.s.l.). Moreover, the future target of the project is to widen the network to the Adriatic countries of Serbia and Albania to create a triangular interferometric array with a side about $500 \mathrm{~km}$ long. Figure 1 shows the location of the two first MEM observatories of L'Aquila and Duronia, and the possible position in the Adriatic area of the interferometer on the drawing board. In Italy, only Duronia will belong to the interferometer. The technological objective of the MEM Project was the development of new low noise instrumentation (Palangio et al., 2008a; 2008b; 2009) and know-how transfer to industry. These instruments are designed for automatic long-term recording of the electromagnetic fields in a wide band of frequency and have been installed in the first two MEM stations. Concerning the data elaboration, the data set of each site can be used individually in a single station approach of the data analysis or, differently, all the data of the network can be analyzed by a multi-station approach using techniques like wide band interferometry (Palangio et al., 2009). The network configuration is essential to separate the natural electromagnetic fields from the artificial ones, and to separate the electromagnetic fields originated in the Earth's interior from those having a source external to the Earth's surface. Concerning the long term monitoring of the electromagnetic field generated in the Earth's crust, in the coming years through the analysis of the Inter Station Magnetic Transfer Functions we will be able to study the possible correlation between the geodynamical processes and the local magnetic field anomalies (Palangio et al., 2007; 2008b). For this purpose the Duronia station will be added to the INGV tectonomagnetic network already existing in Central Italy (Meloni et al., 1998; Masci et al., 2006; 2007).

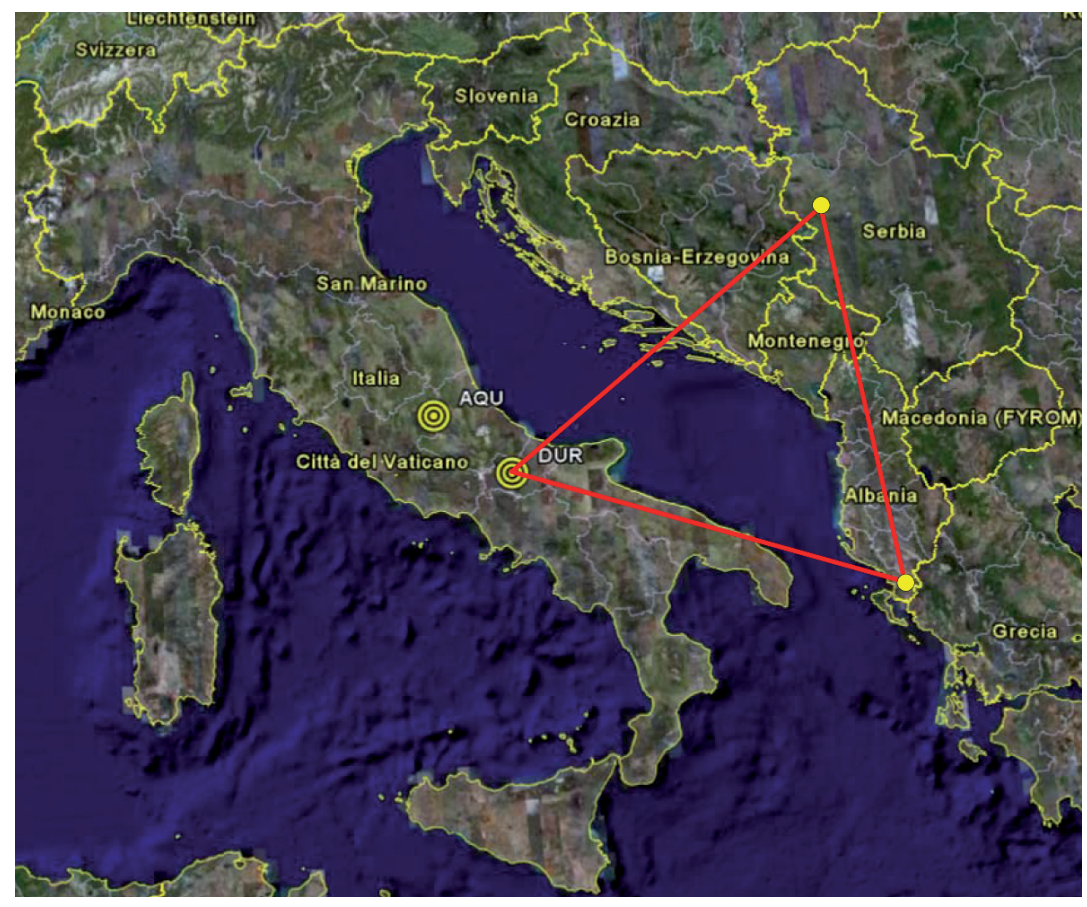

Fig. 1. Location in Central Italy of the first two MEM stations of L'Aquila (AQU) and Duronia (DUR). The red triangle shows the pattern of the planned interferometer in the Adriatic area. 


\section{The electromagnetic field monitoring station of Duronia}

Duronia station was created in the middle of 2007 in an area characterized by low environmental electromagnetic noise starting its operations at the end of the same year. Figures 1,2 and 3 show respectively the location in
Central Italy, the plan and a view of the installation. The station covers an area of about $7500 \mathrm{~m}^{2} 2 \mathrm{~km}$ far away from the village of Duronia and is completely plunged inside a wood of pine trees consisting at the moment of four wooden non-magnetic chalets $(3 \times 2 \mathrm{~m})$ enclosed with a fence made of wood and plastic. The first chalet contains the acquisition

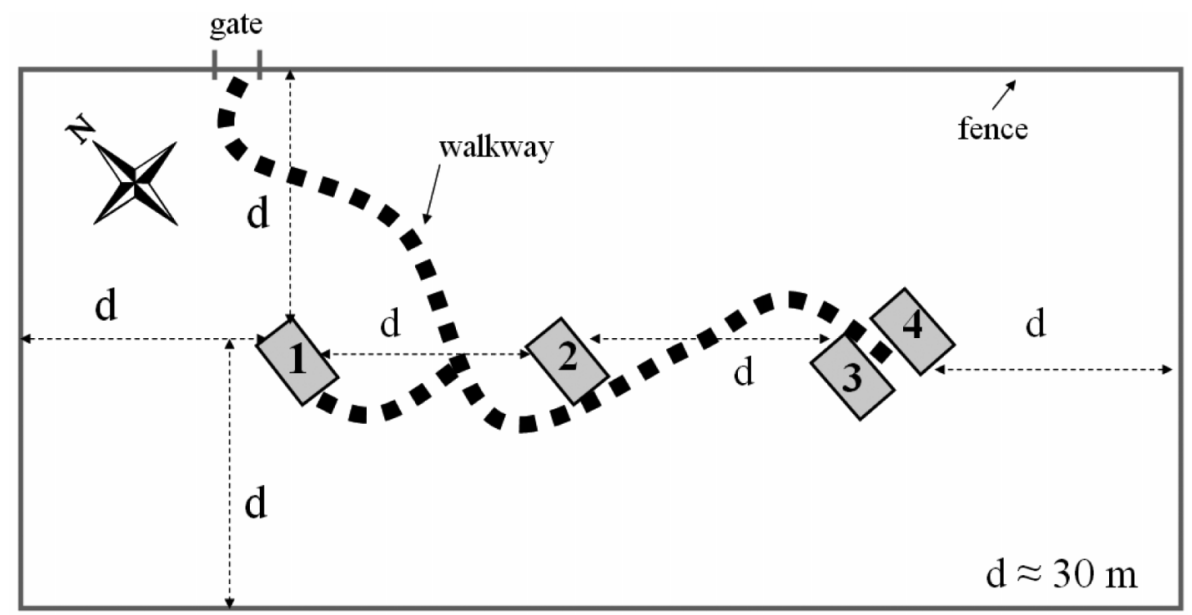

Fig. 2. Plan of Duronia station. The chalet 1 contains the acquisition systems. The chalets 2,3 and 4 , contain the instrumentation.

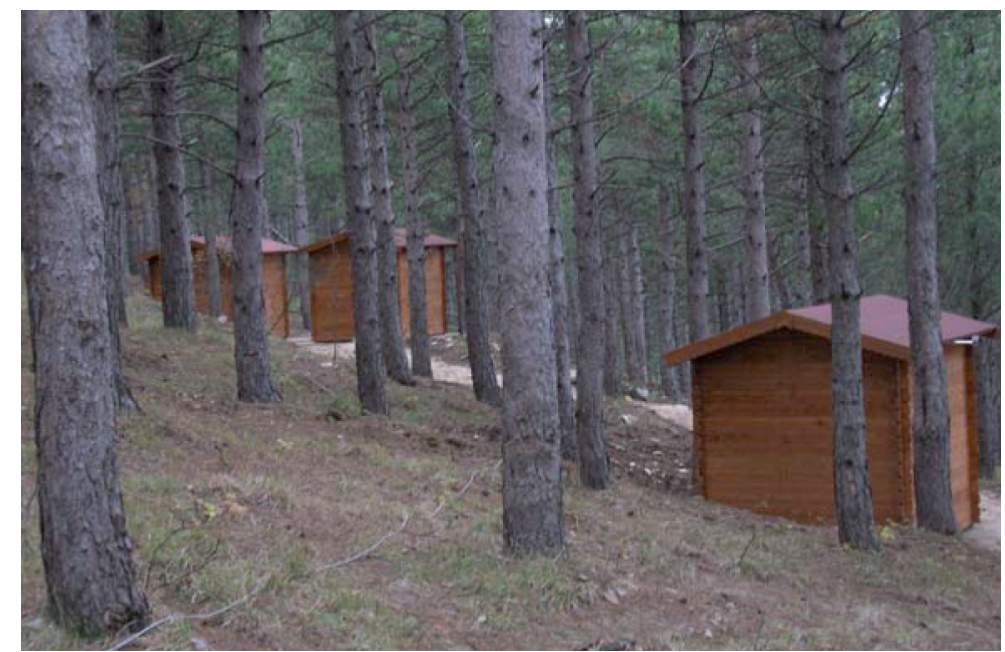

Fig. 3. A view of Duronia station. 
systems, whereas the other three contain the instrumentation. Each chalet is located at least $30 \mathrm{~m}$ away from the fence and placed in the area with a configuration that avoids the instruments affecting each other. The requirements of the International Association of Geomagnetism and Aeronomy (IAGA) concerning the rating of a site as observatory can be summarized in the next five points: 1) the observatory must operate in the long-term to monitor the geomagnetic secular variation; 2) the observatory area must be magneticallepresentative of the surrounding region, both in lower band (secular variation) and in higher band (short-term variation), and the magnetic properties of the region must be unchanging over the long-term; 3 ) horizontal and vertical gradients of the geomagnetic field must be less than $1 \mathrm{nT} / \mathrm{m}$ and the pattern of the geomagnetic field gradient should not change in time; 4) the sensor stands must be stable, their maximum drift from vertical must be less than $15 \% /$ year and the daily variation must be less than 1 "; 5) all materials used in the observatory must be non-magnetic; 6) the presence of the observatory structure should not increase the environmental background electromagnetic noise. We stress that the Duronia installation already fulfils all these requirements as: 1) the position ensures the functionality for a long period; 2) a test campaign was carried out to check requirements 2) and 3): the area and its surroundings has been divided by a $10 \mathrm{~m}$ x $10 \mathrm{~m}$ grid and two proton precession magnetometers were used for the test, one as reference for temporal variation, the other for the measurements of the magnetic field in each grid point; 3 ) the horizontal and vertical maximum gradient of the geomagnetic field are $0.6 \mathrm{nT} / \mathrm{m}$ and $0.3 \mathrm{nT} / \mathrm{m}$ respectively; 4) the stands of the sensors are anchored on bedrock; 5) all the buildings are made of wood and plastic; 6) we have verified that the environmental background electromagnetic noise increases only a few percent in the band around $50 \mathrm{~Hz}$ and its harmonics. In this manner the installation is ready to be a full geomagnetic Observatory as soon as absolute measurements and base line control will be guaranteed.

In the next two sections we briefly describe the instrumentation installed in the station, and show some examples of the first results.

\subsection{Experimental setup}

As previousleported, the instrumentation is located in three of the four chalets (see fig. 2). All the instruments have been developed in the frame of the MEM project, except the total field magnetometer. The instrumentation setup was carried out during the last months of 2007, and the full operation of the station started at the beginning of 2008. At the moment five instruments are installed in the station. The timing of the acquisition system of each instrument is GPS controlled. At the end, we report a brief description of the instruments installed.

\section{1) Triaxial magnetic variometer}

Orientation: HDZ; linear frequencesponse [DC-1Hz]; dynamic range: $\pm 2000 \mathrm{nT}$; resolution: $0.03 \mathrm{nT}$; sampling rate: $0.5 \mathrm{~Hz}$ with a time resolution of $1 \mathrm{~ms}$; filter type: 8 poles elliptic low pass filter. The data of this magnetometer are also stored with an acquisition time of 1 minute.

2) Triaxial high frequency search-coil magnetometer

Orientation: HDZ. Each of the three search coil sensors has a linear frequencesponse in the range $[10 \mathrm{~Hz}-100 \mathrm{kHz}]$. Each sensor is equipped with a low pass antialiasing filter with a $40 \mathrm{kHz}$ cut-off frequency. The output signals are sampled at $100 \mathrm{kHz}$ and are digitized using a 24-bit A/D converter. The dynamic range is between $\pm 10 \mathrm{fT}$ and $\pm 100 \mathrm{nT}$. The magnetic noise level is less than $3 f T / \sqrt{H z}$ over the whole band.

\section{3) Triaxial low frequency search-coil magne- tometer}

Orientation: HDZ. This magnetometer is used to measure geomagnetic field variations in the frequencange $[0.001-40] \mathrm{Hz}$. The noise of the magnetometer is less than $10 \mathrm{pT} / \sqrt{\mathrm{Hz}}$ at a frequency of $0.01 \mathrm{~Hz}$, and less than $20 f T / \sqrt{\mathrm{Hz}}$ above $10 \mathrm{~Hz}$. The sampling rate per channel is $256 \mathrm{~Hz}$, with a sampling resolution of $24 \mathrm{bit}$. The time resolution is $1 \mu \mathrm{s}$ and the accuracy between 


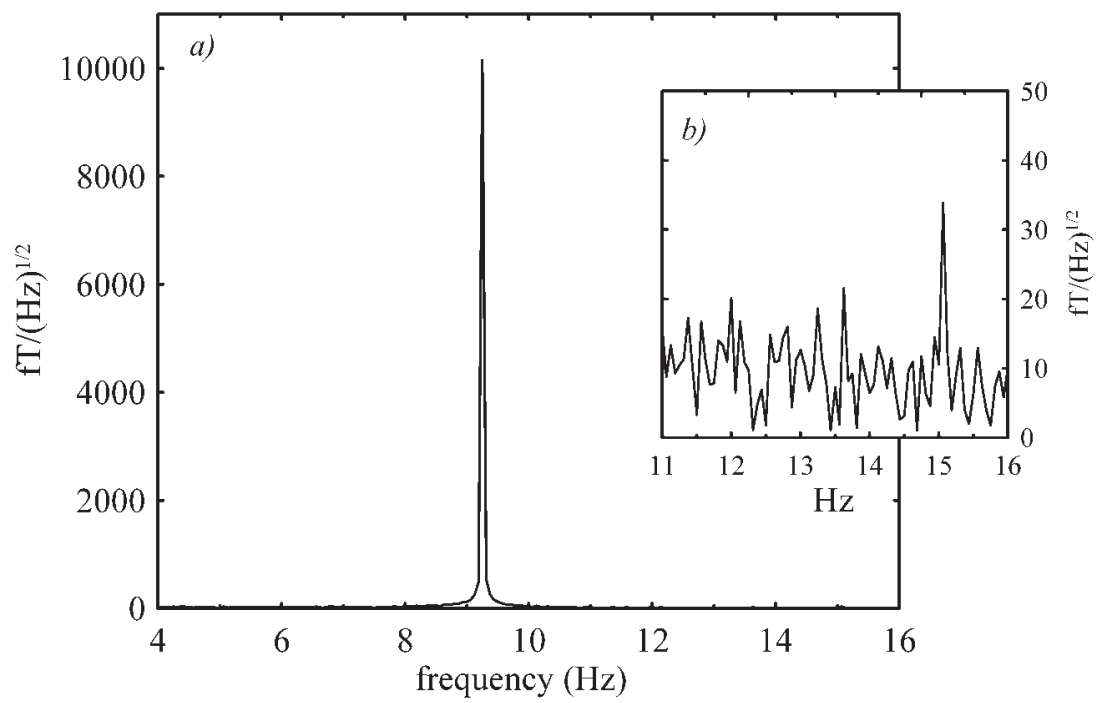

Fig. 4a,b. a) Calibration signal ( $Z$ component) of the triaxial low frequency search-coil magnetometer in the band of frequency [4-16]Hz. b) exploded view of the signal away from the peak as example of background noise in the considered band of frequency. See text for details.

the timing channels is better than $0.1 \mu \mathrm{s}$, because we use three independent $A / D$ circuit, one for each channel $H, D$ and $Z$.

\section{4) Scalar magnetometer}

The scalar magnetometer is an Overhauser magnetometer and it is the only industrial installed instrument. The magnetometer, model Pos1, is produced by the Quantum Magnetometry Laboratory, Russia. The instrument measures the total magnetic field with a sampling rate of $1 \mathrm{~Hz}$ and the time resolution $0.01 \mathrm{~s}$.

5) Telluric electric potential measurement system

This instrument is a typical system used to measure the telluric electric field. The instrument consists of two orthogonal line NS and EW and four electrodes of coal coke distant about $80 \mathrm{~m}$. The electrodes are located outside the fence of the station. The frequency band is [DC- $1 \mathrm{~Hz}]$, and the sensitivity is $1 \mu \mathrm{v} / \mathrm{m}$. The sampling rate is $1 \mathrm{~Hz}$, with a sampling resolution of 24 bit.

Some photos of the instrumentation installed in Duronia can be found in Palangio et al. (2008a; 2008b; 2009). By the end of 2009, a fifth chalet will be built near the gate to the sta- tion (see fig. 2), as new location of the acquisition system. In this way, chalet 1 will be used to house a DIM (Declination Inclination Magnetometer) for absolute magnetic field measurements.

As previousleported, we stress that the principal characteristic of Duronia is the low electromagnetic environmental noise of the site and the low noise of the installed instrumentation. Figure 4 shows the $Z$ component of the signal obtained in the calibration procedure of the triaxial low frequency search-coil magnetometer (instrument 3) in the band [4-16] Hz. The signal used for calibration was generated by a loopantenna triggered off by a $9 \mathrm{~Hz}$ sinusoidal signal. First of all, fig. 4a shows the measured signal peaked at $9 \mathrm{~Hz}$ as expected. Then, the signal away from the peak can be used to evaluate the background noise in this band of frequency. We analyze the $Z$ component because if the sources of the noise are away from the receiver at a distance $>>\lambda$, the boundary conditions over the surface of the conductor (Earth surface) impose that $Z \approx 0$. So, the background noise measured in the band around $9 \mathrm{~Hz}$ can be only due to lo- 


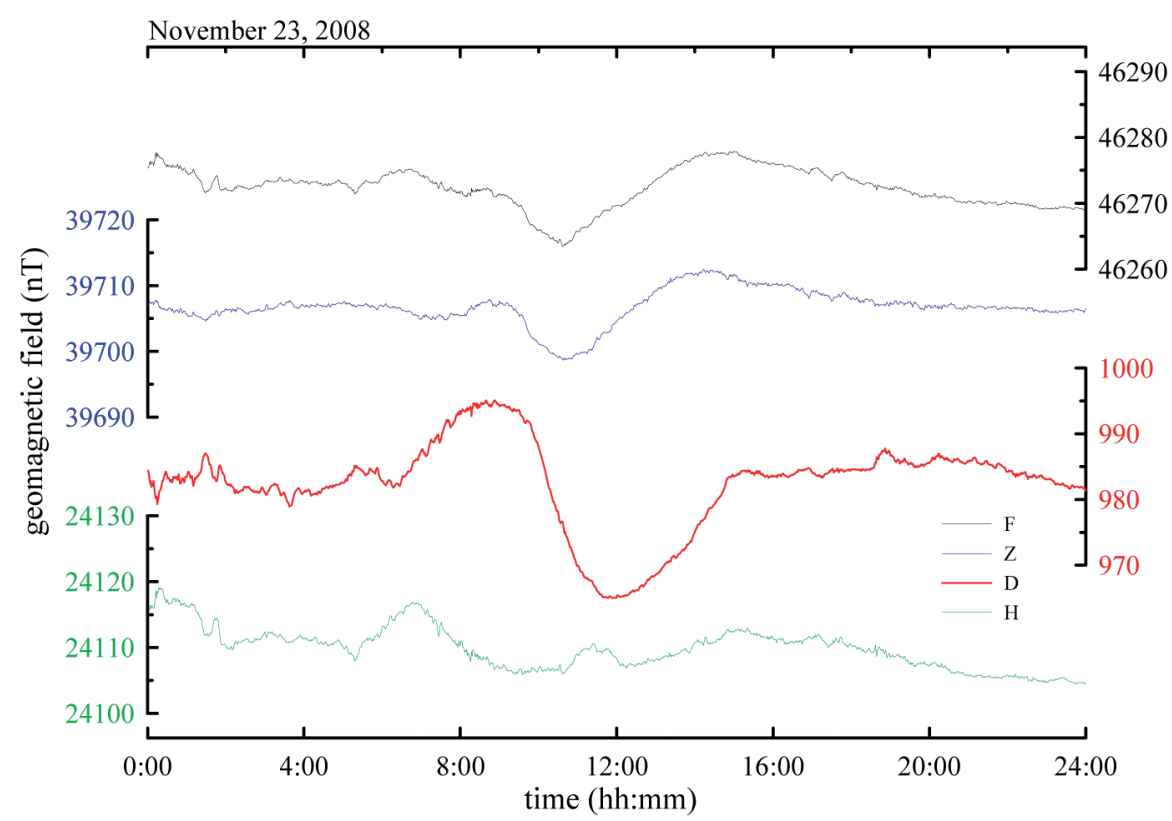

Fig. 5. One daecord of the geomagnetic field components with acquisition time resolution of one minute.

cal sources and to the instrumentation. Figure $4 \mathrm{~b}$ shows an exploded view of the signal in the range of frequency [11-16] Hz, away from the 9 $\mathrm{Hz}$ peak. In the figure can be noted that the background noise is less than $20 f T / \sqrt{H z}$ with sporadic values up to $35 f T / \sqrt{\mathrm{Hz}}$.

Table I lists the timestamps of three instruments of the observatory. Note the time resolution $(1 \mu \mathrm{s})$ of the triaxial low frequency searchcoil magnetometer. This instrument will be used in the future for the wide band interferometry technique.

Figure 5 shows, as an example, one daecord (November 23, 2008) of the geomagnetic field components $H, D, Z$ and the total field $F$, with the typical 1 minute INTERMAGNET acquisition time resolution. Note the low noisiness of all the geomagnetic field components; the noise of the signals is comparable to the noise of the acquisition system and is less than as $0.05 \mathrm{nT}$. Now with the new acquisition system we have an instrumental noise less than $0.02 \mathrm{nT}$.

\subsection{First results}

Due to the very low background noise a detailed observation of the spectral resonance structures of the Schumann Resonance (SR) and the Ionospheric Alfvén Resonator (IAR) can be performed. In literature, the study of SR and IAR is used to infer ionospheric parameters, to monitor the large-scale ionospheric modulation by gravity and planetary waves, the ionosphere-magnetosphere coupling and the planetary temperature (Williams, 1992). Moreover, some authors have found very anomalous effect in SR, probably associated with large earthquakes. (Hayakawa et al., 2005; Nickolaenko et al., 2006; Ohta et al., 2006). SR is the resonance of electromagnetic waves in the Earth-ionosphere cavity with a fundamental frequency of about $8 \mathrm{~Hz}$ and higher order harmonics separated by about $6 \mathrm{~Hz}$ (Schumann, 1952; Schumann and König, 1954). The Earthionosphere cavity is bounded by the Earth's surface and the lower region of the ionosphere, 
Table I. Timestamps of three magnetometers

\begin{tabular}{cccc}
\hline \hline & \multicolumn{3}{c}{ Overhauser magnetometer $[\mathrm{DC}-1 \mathrm{~Hz}]($ sampling rate $=1 \mathrm{~Hz})$} \\
\hline $\mathrm{F}(\mathrm{pT})$ & $\mathrm{s} / \mathrm{n}$ & MM.DD.YY & hh:mm:ss, $1 / 100$ \\
46247635 & 80 & 11.23 .07 & $03: 59: 36,00$ \\
46247627 & 80 & 11.23 .07 & $03: 59: 37,00$ \\
46247608 & 80 & 11.23 .07 & $03: 59: 38,00$ \\
46247608 & 80 & 11.23 .07 & $03: 59: 39,00$ \\
46247613 & 80 & 11.23 .07 & $03: 59: 40,00$ \\
\hline & & Z(a.u. $)$ & hhmmss.ms \\
\hline Triaxial magnetic variometer $[\mathrm{DC}-1 \mathrm{~Hz}](\mathrm{sampling} \mathrm{rate}=0.5 \mathrm{~Hz})$ \\
2.486408 & -0.025959 & -0.506739 & 130720.540 \\
2.486401 & -0.025988 & -0.506726 & 130722.540 \\
2.486394 & -0.025977 & -0.506733 & 130724.540 \\
2.486388 & -0.025965 & -0.506724 & 130726.540 \\
2.486390 & -0.025961 & -0.506727 & 130728.540 \\
2.486392 & -0.025979 & -0.506712 & 130730.540 \\
2.486392 & -0.025982 & -0.506724 & 130732.540 \\
2.486387 & -0.025997 & -0.506685 & 130734.540 \\
2.486387 & -0.025991 & -0.506719 & 130736.540 \\
\hline
\end{tabular}

Triaxial low frequency search-coil magnetometer $[0.001-40] \mathrm{Hz}($ sampling rate $=256 \mathrm{~Hz})$

\begin{tabular}{ccccc}
\hline X(a.u.) & Y(a.u.) & Z(a.u.) & YYYY MM DD & hh mm ss. $\mu$ s \\
7933519 & 8726035 & 8348616 & 20090116 & 064612.526554 \\
7933415 & 8726055 & 8348879 & 20090116 & 064612.530461 \\
7933552 & 8725980 & 8348716 & 20090116 & 064612.534369 \\
7933660 & 8725985 & 8348988 & 20090116 & 064612.538276 \\
7933955 & 8726016 & 8349040 & 20090116 & 064612.542183 \\
7933863 & 8726010 & 8348720 & 20090116 & 064612.546090 \\
7933563 & 8725944 & 8348931 & 20090116 & 064612.549997 \\
7933728 & 8725927 & 8348611 & 20090116 & 064612.553905 \\
7933752 & 8725920 & 8348444 & 20090116 & 064612.557812 \\
7933647 & 8725932 & 8348380 & 20090116 & 064612.561719 \\
7933756 & 8725928 & 8348207 & 20090116 & 064612.565626 \\
7933664 & 8725952 & 8347955 & 20090116 & 064612.569534 \\
7933779 & 8725968 & 8347999 & 20090116 & 064612.573441 \\
7933707 & 8725876 & 8348575 & 20090116 & 064612.577348 \\
7933631 & 8725888 & 8348775 & 20090116 & 064612.581255 \\
7933595 & 8725883 & 8348588 & 20090116 & 064612.585163 \\
7933487 & 8725928 & 8348763 & 20090116 & 064612.589070 \\
\hline
\end{tabular}




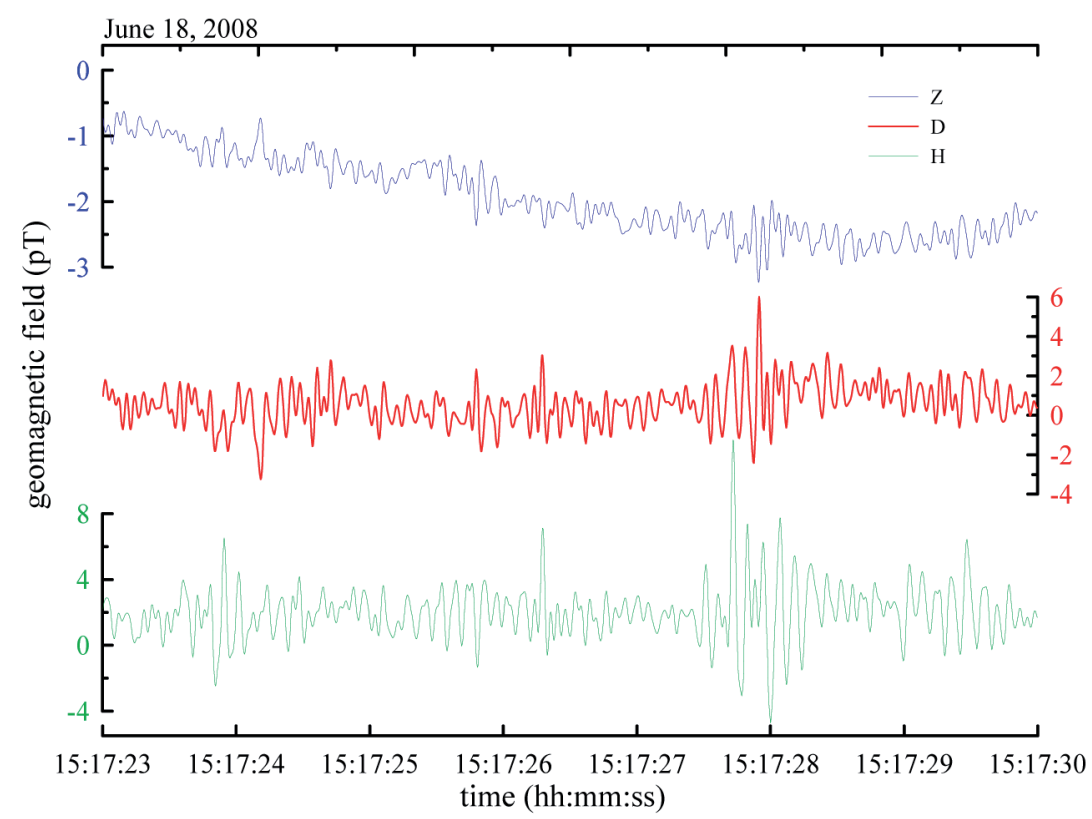

Fig. 6. An example of $7 \mathrm{~s}$ time domain record with a sampling rate of $256 \mathrm{~Hz}$. Note the presence of the SR Q-bursts.

the so called $D$-layer. This cavity can support, as quasi-waveguide, electromagnetic standing waves whose wavelengths are comparable to the planetary dimension.

The fundamental mode of SR is a quasistanding wave in the Earth-ionosphere cavity with a wavelength of about the Earth's circumference. Changes in the $D$ region ionization can modify the SR parameters. It is well assumed that lightning dischargers due to thunderstorm activity are the main excitation source of the SR (Sentman, 1995).

The low frequency components of these electromagnetic transients can circle the globe several times, and therefore produce resonant spectrum lines. Figure 6 shows an example of 7 $\mathrm{s}$ time domain record (sampling rate $256 \mathrm{~Hz}$ : frequencange [0.001 - 40] Hz) acquired on June 18, 2008. The geomagnetic field components show a continuous background with the superimposition of some typical SR Q-bursts. Figure 7 shows an example about the spectral resonance structure of SR obtained from the data collected on February 14, 2008 between 20:00 UT and 21:00 UT. The power spectral densities shown in fig. 7, and later in figs. 8 and 9, are estimated via the maximum entropy method to improve the spectral resolution between the peaks (Marple, 1987). In fig. 7, the presence of the first 4 SR harmonics is clearly evident in all three components.

The $Z$ component also shows two peaks at frequencies $\approx 16.7 \mathrm{~Hz}$ and $\approx 26.2 \mathrm{~Hz}$ due to artificial signals; the first signal is certainly due to the German railway network. This artificial signal is produced by the uncoupled current component which flows deeper in the Earth's crust and depends on the resistivity of the soil and on the linear extension of the railway network (Palangio et al., 1991).

The two artificial signals are evident in the vertical component, whereas they do not appear in the horizontal components because the spectral amplitude of the natural signals on the horizontal components is thirty times larger than the vertical component. Figure 8 shows the SR 


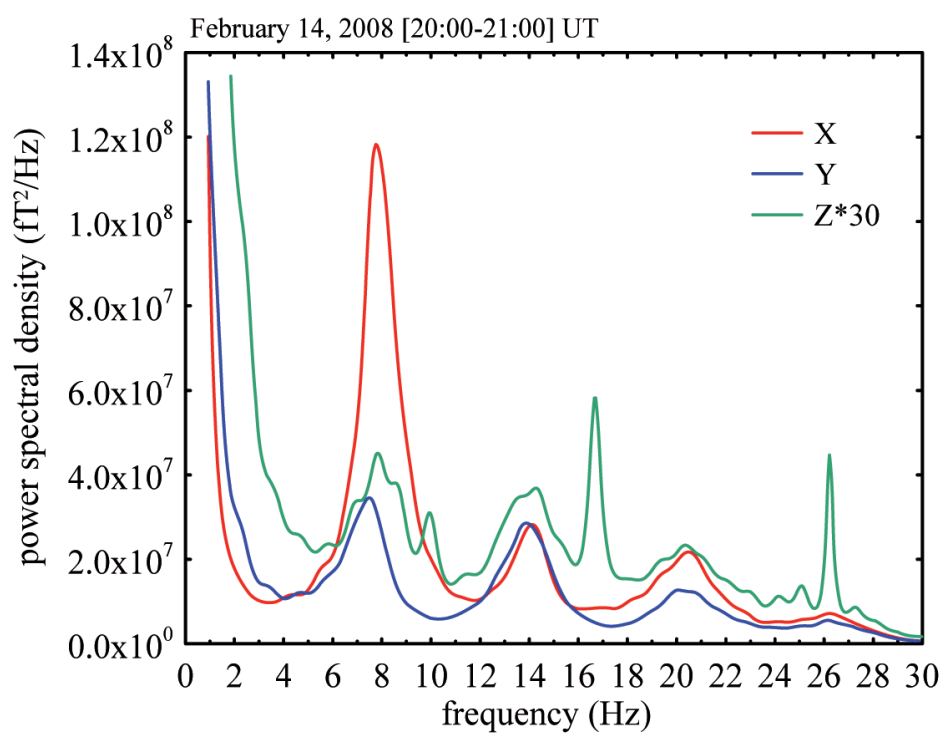

Fig. 7. An example of the SR spectral resonance structures. The first four harmonics are evident in all the three components. The $Z$ component shows also two peaks at frequencies $\approx 16.7 \mathrm{~Hz}$ and $\approx 26.2 \mathrm{~Hz}$ due to artificial signals. For clarity the values of the $Z$ component are multiplied by 30 .

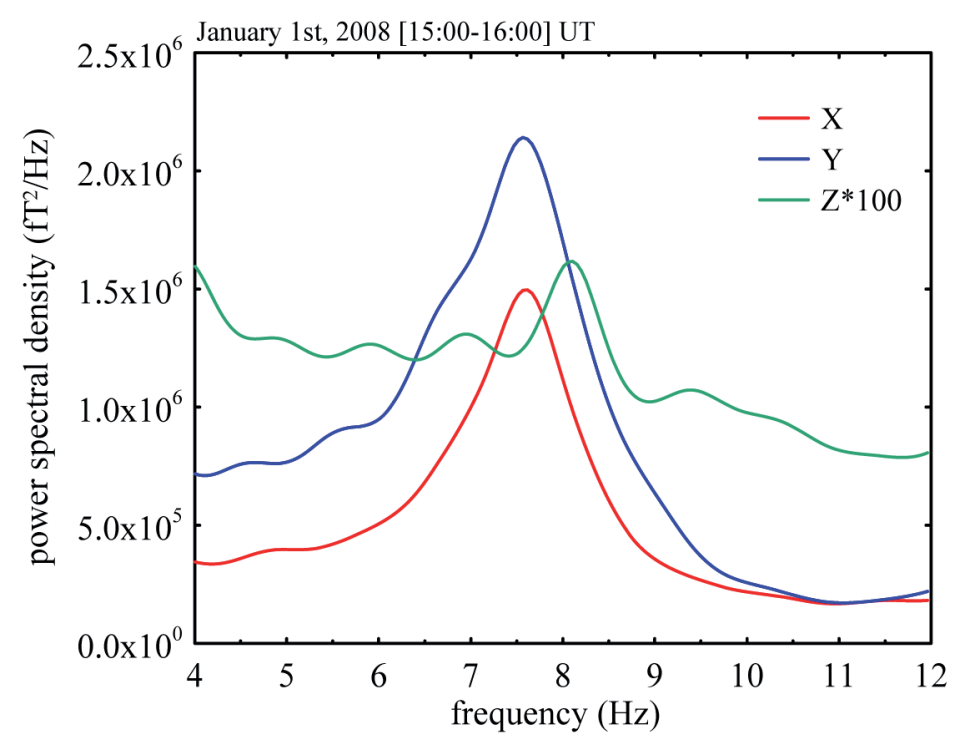

Fig. 8. An example of the SR fundamental mode. Note that the peak frequency $f_{x}=7.6 \mathrm{~Hz}$ is equal to $f_{y}$, whereas $f_{z}=8.2 \mathrm{~Hz}$. For clarity the values of the $Z$ component are multiplied by 100 . 


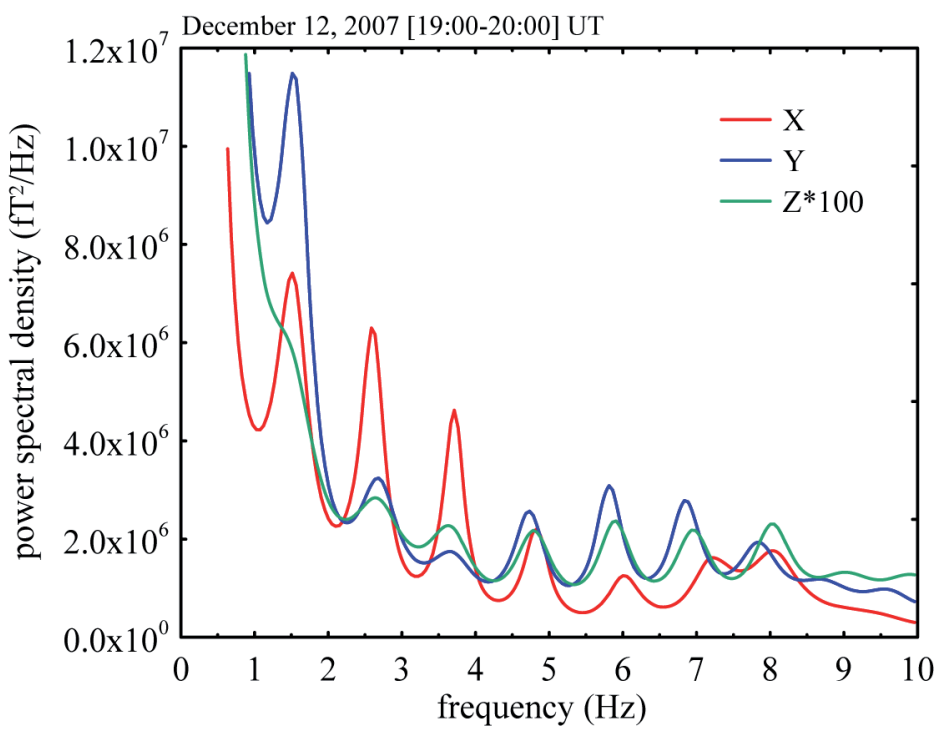

Fig. 9. An example of the spectral resonance structures of IAR. The frequency interval between the peaks is about $1 \mathrm{~Hz}$. For clarity the values of the $Z$ component are multiplied by 100 .

fundamental mode obtained from the data collected on January 1, 2008 between 15:00 UT and 16:00 UT. The frequencies of the peaks are $f_{x}=7.6 \mathrm{~Hz}, f_{y}=7.6 \mathrm{~Hz}$ and $f_{z}=8.0 \mathrm{~Hz}$. In this case $f_{x} \equiv f_{y}$, but generally, the frequencies $f_{i}$ of the three components are different (Nickolaenko and M. Hayakawa, 2002). At frequencies that are below the SR there is another kind of resonance, named IAR.

The Ionospheric Alfvén Resonator is the definition of the vertical structure of the plasma density decay from the ionosphere to the magnetosphere. The existence of this resonator was proposed for the first time by Polyakov (1976). Alfvén waves propagating along the geomagnetic field lines are partialleflected from regions of large Alfvén velocity gradient.

The lower boundary of the resonator coincides with the ionospheric $E$-layer.

The upper boundary of the resonator is located at an altitude of about $3000 \mathrm{~km}$ where the Alfvén waves are partialleflected from the region of large Alfvén velocity gradient due to the rapid decrease of the plasma density (Surkov et al., 2004).
IAR resonance spectrum shows daily and latitude dependence and it is regularly observed, especially at night time, at middle latitudes.

Usually the resonance frequencanges in the interval $[0.5-7.0] \mathrm{Hz}$, while the frequency interval $\Delta f$ between the peaks ranges in the interval $[0.5-3.0] \mathrm{Hz}$ at mid latitudes (Belayaev et al., 2000; Hayakawa et al., 2004). As for the $\mathrm{SR}$, it is supposed that the electromagnetic emissions due to the global thunderstorm activity and the vertical neutral wind are the main excitation source of IAR (Belayaev et al., 1989).

Figure 9 shows an example of the spectral resonance structure of IAR calculated from the data collected in Duronia on December 29, 2007 between 19:00 UT and 20:00 UT.

In this case, the IAR resonance structure shows five peaks at frequencies below $8 \mathrm{~Hz}$ with a frequency interval between the peaks about $1 \mathrm{~Hz}$. Figure 9 is only an example of a spectrum of what we assume to be IAR; in the future a more in- depth study of IAR will be planned. 


\section{Conclusions}

A new Italian station to monitor the electromagnetic fields was set up in Duronia with the AIM to develop a Geomagnetic Observatory.

The peculiarity of the site of Duronia is the low electromagnetic environmental noise. We have briefly described the experimental setup showing the characteristics of the installed instrumentation. Some preliminaresults are shown concerning the study of the spectral resonance structure of the Schumann Resonance (SR), in the Earth-ionospere cavity, and the Ionospheric Alfvén Resonator (IAR). When many data are available, we will be able to plan a systematic study on the changes in SR and IAR parameters, and the study of the electromagnetic anomalies possibly linked with the tectonic activity. In addition, the project to set up a triangle interferometer in the Adriatic area is reported.

\section{Acknowledgements}

The authors are greatly indebted to the ARPA Molise staff for the basic support in the creation of the Observatory of Duronia installation.

The authors thank the local administration, and the whole community of Duronia for their invaluable support. A special thanks to Vincenzina and Giovanni Manzo, and Benito De Vincenzo for their warm hospitality.

The authors are grateful to two anonymous reviewers and to Dr. Antonio Meloni for their comments.

\section{REFERENCES}

Belayaev, P.P., S.V. Polyakov, V.O. Rapoport and V.Y. TRAKHTENGERTS (1989): Theory of the formation of resonance structure of the atmospheric electromagnetic background noise in the range of short-period, $R a$ diofizika, 32, 802-810.

Belayaev, P.P., S. V. Polyakov, E.N. ERmakova and S.V. ISAEV (2000): Solar cycle variations in the ionospheric Alfvén resonator 1985-1995, J. Atmos. Terr. Phys., 62, 239-248.

Bianchi, C. and A. Meloni (2008): Natural and man-made terrestrial electromagnetic noise: an outlook, Ann. Geoph-Italy, 3, 435-445.
Hayakawa, M., K. Ohta, A.P. Nickolaenko and Y. Ando (2005): Anomalous effect in Schumann resonance phenomena observed in Japan, possibly associated with the Chi-chi earthquake in Taiwan, Ann. Geophys., 23 , 1335-1346.

Hayakawa, M., O.A. Molchanov, A.Y. Schektov and E. FEDOROV (2004): Observation of ionospheric Alfvén resonance at a middle latitude station, Adv. Polar Upper Atmos. Res., 18, 55-76.

MARPLE, S.L. Jr. (1987): Digital spectral analysis with applications, (Prentice-Hall), pp. 492.

Masci, F., P. Palangio and A. Meloni (2006): The INGV tectonomagnetic network: 2004-2005 preliminary dataset analysis, Nat. Hazards Earth Sys., 6, 773-777.

Masci, F., P. Palangio, M. Di Persio and C. Di Lorenzo (2007): The development of the INGV tectonomagnetic network in the frame of the MEM Project, Nat. Hazards Earth Syst. Sci., 7, 473-478.

Meloni, A., F. Mele and P. Palangio (1998): Tectonomagnetic field observations in central Italy 1989-1995, Phys. Earth Planet In, 105, 145-152.

NickolaENKo, A.P. and M. HAYAKAWA (2002): Resonances in the Earth-Ionosphere Cavity, (Kluwer Acad. Pub.), vol. 19, pp. 380.

Nickolaenko, A.P., M. Hayakawa, M. Sekiguchi, Y. ANDO and K. ОнтA (2006): Model modifications in Schumann resonance intensity caused by a localized ionosphere disturbante over the earthquake epicenter, Ann. Geophys., 24, 567-575.

Ohta, K., N. Watanabe and M. Hayakawa (2006): Survey of anomluos Schumann resonance phenomena observed in Japan, in possible association with earthquakes in Taiwan, Phys. Chem. Earth, 31, 397-402.

Palangio, P., M. Marchetti and L. Di Diego (1991): Rumore elettromagnetico prodotto dalle ferrovie elettrificate. Effetti sulle misure magnetotelluriche e geomagnetiche, Atti del X Convegno Annuale del G.N.G.T.S., 126-139.

Palangio, P., C. Di Lorenzo, F. Masci and M. Di Persio (2007): The study of the electromagnetic anomalies linked with the Earth's crustal activity in the frequency band $[0.001 \mathrm{~Hz}-100 \mathrm{kHz}]$, Nat. Hazards Earth Syst. Sci., 7, 507-511.

Palangio, P., F. Masci, M. Di Persio and C. Di Lorenzo (2008a): Electromagnetic field measuremets in ULFELF-VLF $[0.001 \mathrm{~Hz}-100 \mathrm{kHz}]$ bands, Advances in Geosciences, 14, 69-73.

Palangio, P., C. Di Lorenzo, M. Di Persio, F. Masci, S. Minajlovic, L. Santarelli and A. Meloni (2008b): Electromagnetic monitoring of the Earth's interior in the frame of MEM project, Ann. Geoph-Italy, 51, 225236.

Palangio, P., F. Masci, C. Di Lorenzo and M. Di Persio (2009): The wideband $[0.001 \mathrm{~Hz}-100 \mathrm{kHz}]$ Interferometry project in Central Italy, Geophys. Prospecting, 57 (4), 729-739.

POLYAKOV, S.V. (1976): On properties of a ionospheric Alfén resonator, in Symposium KAPG on Solar-Terrestrial Physics, Nauka, Moscow, III, 72-73.

Sentman, D. D. (1995): Schumann resonances, in Handbook of Atmospheric Electrodynamics, vol. 1, (Ed. Volland, Boca Raton), 267-296.

SchumanN, W.O. (1952): Über die strahlungslosen Eigen- 
schwingungen einer leitenden Kugel, die von einer Luftschicht und einer Ionosphärenhülle umgeben ist, Zeitschrift für Naturforschung, 7a, 149 -152.

SchumanN, W.O. and H. KöNIG (1954): Über die Beobactung von Atmospherics bei geringsten Frequenzen, Naturwiss, 41, 183-184.

Surkov, V.V., O. A. Pokhotelov, M. Parrot, E.N. FeDOROV and M. HAYAKAWA (2004): Excitation of the ionospheric resonance cavity by neutral winds at middle latitudes, Ann. Geophys., 22, 2877-2889.

WiLliams, E.R. (1992): The Schumann Resonance: A global tropical thermometer, Science, 256, 1184-1187.

(received, June 23, 2008; 